\title{
BMJ Open Low uric acid levels in patients with Parkinson's disease: evidence from meta-analysis
}

\author{
Liang Shen, Hong-Fang Ji
}

To cite: Shen L, Ji H-F. Low uric acid levels in patients with Parkinson's disease: evidence from meta-analysis. BMJ Open 2013;3:e003620. doi:10.1136/bmjopen-2013003620

- Prepublication history for this paper is available online. To view these files please visit the journal online (http://dx.doi.org/10.1136/ bmjopen-2013-003620)

Received 20 July 2013 Revised 17 October 2013 Accepted 18 October 2013

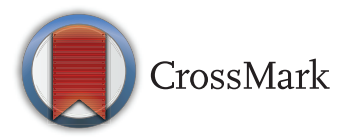

Shandong Provincial Research Center for Bioinformatic Engineering and Technique, Shandong University of Technology, Zibo, People's Republic of China

Correspondence to Dr Hong-Fang Ji; jhf@sdut.edu.cn

\section{ABSTRACT}

Objective: The association between Parkinson's disease (PD) and uric acid levels has gained intensive interest in recent years. We applied meta-analysis to investigate serum uric acid levels in patients with $\mathrm{PD}$ in comparison with healthy controls.

Design: We searched three electronic databases and reference lists up to January 2013. Two collaborators reviewed all the articles and data disagreement was resolved through discussion. Six studies met the eligibility criteria and were included in the metaanalysis of uric acid levels in patients with PD in comparison with controls.

Participants: 1217 patients with PD and 1276 matched healthy controls.

Results: The meta-analysis results showed that patients with PD had lower levels of uric acid than healthy controls (summary standardised mean difference (SMD) $=-0.52,95 \% \mathrm{Cl}(-0.72$ to -0.31$))$. Further gender subgroup analysis (summary SMD= $-0.56,95 \% \mathrm{Cl}(-0.72$ to -0.41$)$ for women; summary $\mathrm{SMD}=-0.62,95 \% \mathrm{Cl}(-0.94$ to -0.31$)$ for men) indicated lower uric acid levels in patients with PD than healthy controls in women and men.

Conclusions: It was found that patients with PD had lower serum levels of uric acid than healthy controls and this association was more significant in men than in women. More efforts are encouraged to explore the prognostic and therapeutic implications for PD of the present findings.

\section{INTRODUCTION}

Parkinson's disease (PD) is a progressive neurodegenerative disorder and with the accelerated ageing of human society, the prevalence of this disorder is expected to rise steadily in future. ${ }^{12}$ The cause of PD remains unclear, but oxidative stress has been strongly implicated. ${ }^{3}$ Uric acid, an important endogenous antioxidant with high concentrations in serum and in brain, can prevent oxidative stress owing to its ability to scavenge various reactive oxygen species (ROS) and reactive nitrogen species (RNS). ${ }^{4}$ Uric acid has been hypothesised to reduce oxidative stress on

\section{Strengths and limitations of this study}

- Confirmed the lower serum uric acid levels in patients with Parkinson's disease than in healthy controls.

- Major limitation is the relatively limited studies included.

the central nervous system. ${ }^{5}$ Therefore, in recent years the association between uric acid levels and PD, has gained intensive interest. ${ }^{6-11}$ It has been widely demonstrated by many studies that high levels of uric acid predict a decreased risk of developing PD. ${ }^{10}{ }^{11}$ In recent years, accumulating evidence indicated the difference in uric acid levels between patients with PD and healthy controls, ${ }^{8} 912$ while there is no comprehensive evaluation on this issue. The purpose of the present study was to perform a meta-analysis to evaluate serum uric acid levels in patients with PD in comparison with healthy controls, which has important implications for the prevention and treatment of this disease.

\section{MATERIALS AND METHODS \\ Literature search}

We identified procurable published articles in English through a computerised PubMed, EMBASE and Cochrane Library databases search for English language literature up to January 2013. We used the following key words to search the aforementioned databases: uric acid or urate and PD. We also examined conference proceedings, and the references in all articles retrieved were crosschecked to obtain all pertinent publications on the uric acid levels in patients with PD.

\section{Selection criteria}

For inclusion in the meta-analysis of uric acid levels in patients with PD in comparison with controls, we considered only papers showing 
Figure 1 Selection of studies for inclusion in the present meta-analysis.

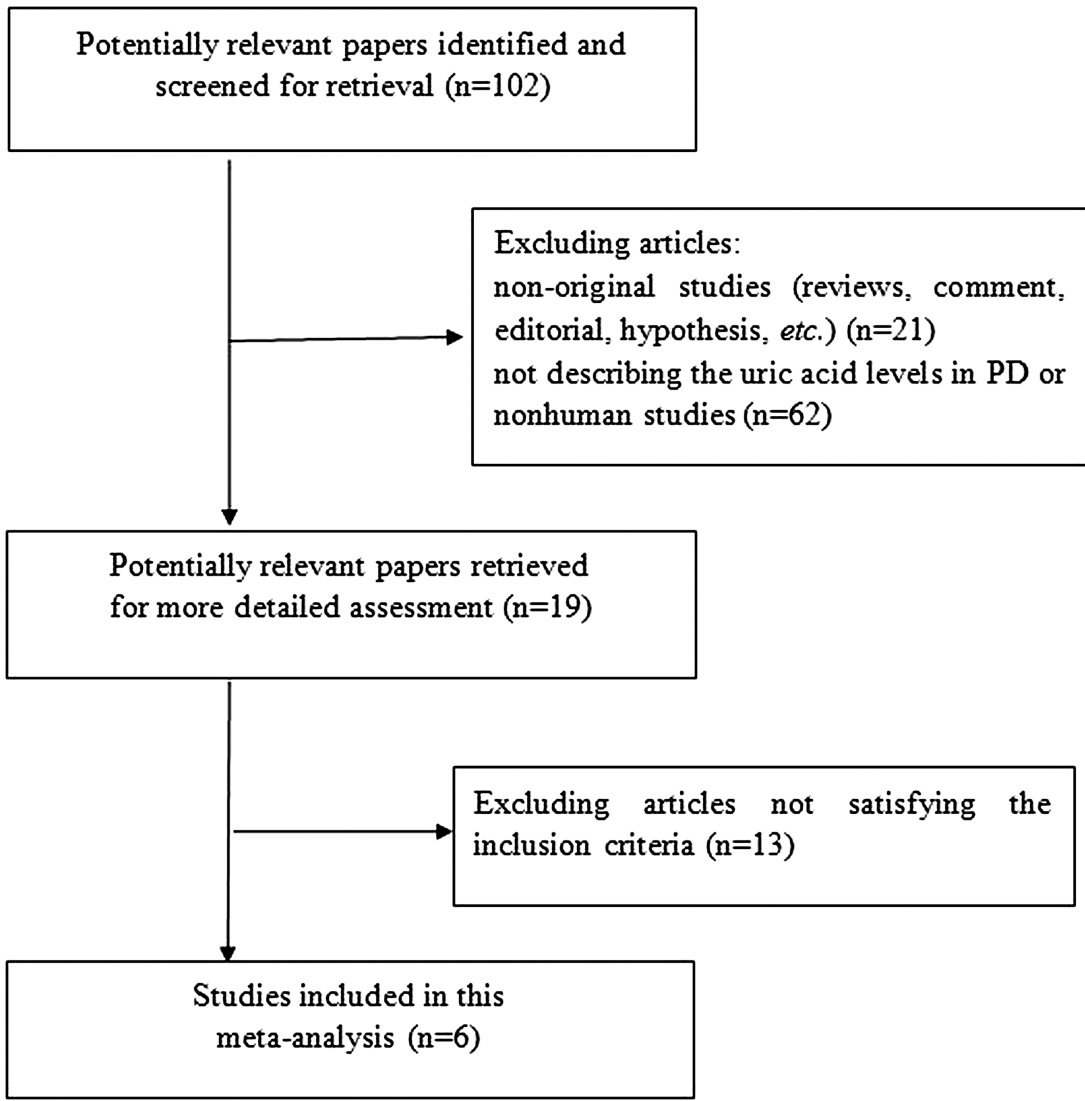

comparative analysis of patients with PD against healthy controls. We also required that studies explicitly present uric acid mean and SD values for patients and control groups. Two collaborators reviewed all articles and data disagreement was resolved through discussion. In total, six studies were identified and included in the meta-analysis on uric acid levels in patients with PD. ${ }^{8}{ }^{12-15}$ In each study, the patients with PD were diagnosed according to the clinical criteria of the UK Parkinson's Disease Society Brain Bank. The inclusion criteria for the control must be age-matched and have no PD history. In the patients with PD and control groups, the individuals with current use of uric acid lowering agents were excluded. In four of the six studies, severity of the diseases was evaluated according to Hoehn-Yahr (H-Y) stage diagnosis criteria and the patients were divided into several subgroups. ${ }^{9}{ }^{13-15}$

\section{Data extraction and meta-analysis}

We extracted information from the six included papers including first author, year of publication, the number of PD cases and healthy controls, the mean of uric acid levels and the SD of uric acid levels. We used the data to obtain $95 \%$ CI and the SMD. Sex subgroup analysis was also conducted to investigate the effect of gender on the uric acid levels in patients with PD. Statistical computation was performed using the STATA V.12.0 statistical software (StataCorp LP, College Station, Texas, USA).

\section{RESULTS}

Search results and characteristics of the included studies

The details of study selection processes were shown in figure 1. Through the computerised databases search, 102 potentially relevant papers were identified and screened for retrieval. After reviewing the title and abstract, 83 studies, which included non-original or nonhuman studies, or those not investigating the uric acid levels in patients with $\mathrm{PD}$, were excluded. Of the remaining 19 studies, 13 were then excluded for not satisfying the inclusion criteria based on full-text review. Finally, there were six studies in total that met the eligibility criteria and were included in the meta-analysis. 8 9 12-15 Among the six studies, two were conducted in Finland, ${ }^{8} 12$ two in China, ${ }^{13} 15$ one in Greece ${ }^{9}$ and one in Spain. ${ }^{14}$ The participants included in each of the six studies included both male and female patients.

\section{Uric acid levels in patients with PD}

A total of 1217 patients with PD and 1276 healthy controls were enrolled in the six studies. ${ }^{8} \quad 9 \quad 12-15$ The extracted information from each paper including first author, year of publication, the number of cases and controls, the mean levels of uric acid and the SD of uric acid levels, is shown in table 1. According to the meta-analysis results as shown in figure 2, it was found that patients with PD had lower serum levels of uric acid than healthy controls (summary $\mathrm{SMD}=-0.52,95 \%$ CI $(-0.72$ to -0.31$))$ and the six sets of results showed statistically significant heterogeneity $\left(\mathrm{p}=0.001, \mathrm{I}^{2}=75.6 \%\right)$. 
Table 1 Summary of studies included in the meta-analysis of uric acid levels in patients with PD

\begin{tabular}{|c|c|c|c|c|c|c|c|c|c|}
\hline \multirow[b]{2}{*}{ References } & \multirow[b]{2}{*}{ Year } & \multirow[b]{2}{*}{ Country } & \multicolumn{2}{|l|}{$\mathbf{N}$} & \multicolumn{2}{|c|}{ Uric acid levels ( $\mu \mathrm{M} / \mathrm{L})$} & \multirow[b]{2}{*}{ Weight (\%) } & \multirow[b]{2}{*}{ SMD } & \multirow[b]{2}{*}{$95 \% \mathrm{Cl}$} \\
\hline & & & $\overline{P D}$ & Control & PD & Control & & & \\
\hline$\overline{\text { Annanmaki et } a \beta}$ & 2007 & Finland & 40 & 29 & $278.5 \pm 77.4$ & $319.7 \pm 76.0$ & 10.64 & -0.54 & $(-1.02$ to -0.05$)$ \\
\hline Andreadou et a $\rho$ & 2009 & Greece & 43 & 47 & $325.4 \pm 83.3$ & $378.3 \pm 255.8$ & 12.74 & -0.27 & $(-0.69$ to 0.14$)$ \\
\hline Annanmaki et al ${ }^{12}$ & 2011 & Finland & 28 & 12 & $285.0 \pm 63.8$ & $309.1 \pm 87.5$ & 6.72 & -0.34 & $(-1.02$ to 0.34$)$ \\
\hline Zhang et $a l^{13}$ & 2012 & China & 534 & 614 & $278.10 \pm 87.31$ & $348.17 \pm 86.25$ & 24.88 & -0.81 & $(-0.93$ to -0.69$)$ \\
\hline Sun et $a 1^{15}$ & 2012 & China & 411 & 396 & $243.38 \pm 78.91$ & $282.97 \pm 90.80$ & 24.15 & -0.47 & $(-0.61$ to -0.33$)$ \\
\hline Jesús et $a l^{14}$ & 2013 & Spain & 161 & 178 & $278.4 \pm 98.7$ & $319.4 \pm 95.2$ & 20.87 & -0.42 & $(-0.64$ to -0.21$)$ \\
\hline
\end{tabular}

\section{Sex subgroup analysis of uric acid levels} in patients with $\mathrm{PD}$

To explore the effect of gender on the uric acid levels in patients with PD, we then performed a sex subgroup analysis. Among the six studies, four present the information of women and men subgroups as shown in table 2. ${ }^{9} 13-15$ In the women subgroup, there were 489 patients with PD and 516 healthy controls in total. In total, 660 patients with PD and 719 healthy controls were included in men subgroup analysis. The meta-analysis results (summary $\mathrm{SMD}=-0.56,95 \%$ CI $(-0.72$ to -0.41$)$, figure 3$)$ indicated lower uric acid levels in patients with PD than healthy controls for women. Similar results were also obtained for men (summary $\mathrm{SMD}=-0.62,95 \%$ CI $(-0.94$ to -0.31 ), figure 3) indicative of lower uric acid levels in patients with PD. In addition, according to the present results this association was relatively significant in men more than in women.

\section{DISCUSSION}

This meta-analysis suggests that patients with PD had lower serum levels of uric acid than healthy controls. To our knowledge, this is the first meta-analysis of uric acid levels in patients with PD. The antioxidant potential of uric acid should be the predominant mechanism underlying the association between uric acid levels and PD. Despite the cause of PD is complicated, oxidative stress, which is caused by increased content of ROS and/or RNS damage, has widely been accepted to be implicated. ${ }^{31617}$ Uric acid is an important endogenous antioxidant that can scavenge ROS and RNS and also chelate iron ion. ${ }^{4} 1819$ It has been reported that in humans over half of the antioxidant capacity of blood plasma arises from uric acid. ${ }^{20}$ For instance, uric acid can scavenge peroxynitrite, ${ }^{21} 22$ which is proven to play an important role in the pathogenesis of $\mathrm{PD}^{23}{ }^{24}$ Therefore, the protective antioxidant effects of high levels of uric acid may lower the risk of PD, while the lower level of uric acid in patients with PD may arise from the increased consumption of uric acid as a scavenger in alleviating the oxidative stress. In addition, it has been found that SLC2A9 splice variants act as the most effective of all uric acid transporters. ${ }^{25} \mathrm{~A}$ recent study investigated the association between SLC2A9 polymorphisms and age at the onset of PD and provides evidence of an association between age at the onset in PD and variants within the SLC2A9 gene ${ }^{26}$ which may account for the observed lower uric acid levels in patients with PD than in the controls.

Certainly, there may exist other mechanisms to interpret the association between uric acid levels and PD as
Figure 2 Overall pooled estimate of standardised mean difference (SMD) and $95 \% \mathrm{Cl}$ of uric acid levels in Parkinson's disease and healthy controls.

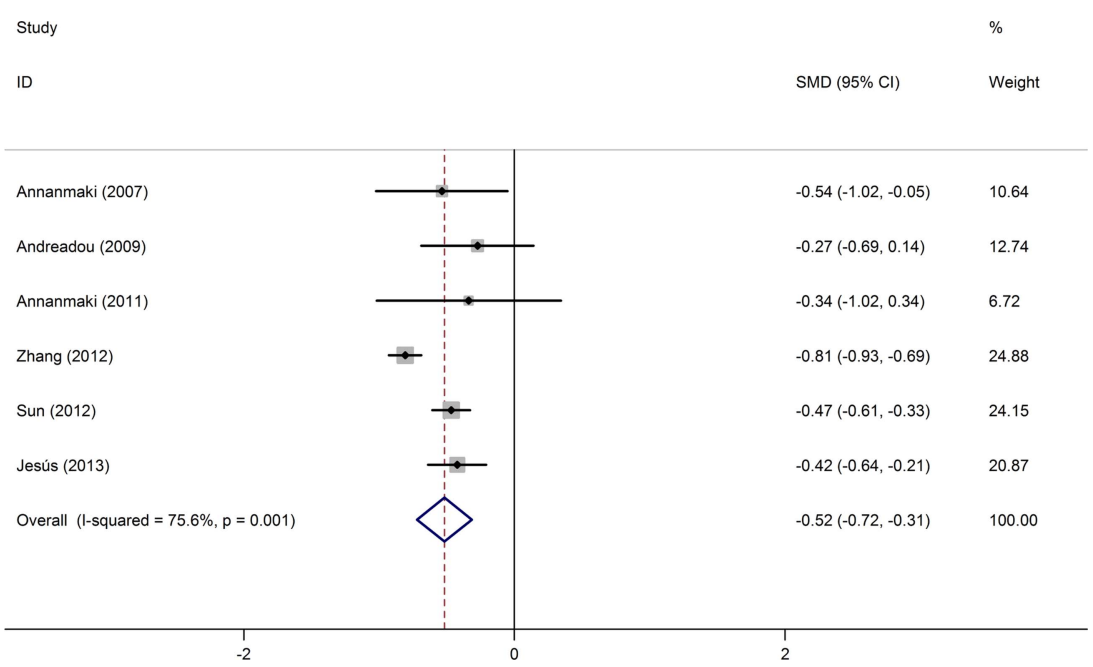


Table 2 Summary of studies included in the sex subgroup meta-analysis of uric acid levels in patients with PD

\begin{tabular}{|c|c|c|c|c|c|c|c|c|}
\hline \multirow[b]{2}{*}{ Subgroup } & \multirow[b]{2}{*}{ References } & \multicolumn{2}{|l|}{$\mathbf{N}$} & \multicolumn{2}{|c|}{ Uric acid levels $(\mu \mathrm{M} / L)$} & \multirow[b]{2}{*}{ Weight (\%) } & \multirow[b]{2}{*}{ SMD } & \multirow[b]{2}{*}{$95 \% \mathrm{Cl}$} \\
\hline & & $\overline{P D}$ & Control & $\overline{P D}$ & Control & & & \\
\hline \multirow[t]{4}{*}{ Women } & Andreadou et $a^{\rho}$ & 21 & 22 & $275.4 \pm 69.0$ & $323.0 \pm 94.0$ & 5.82 & -0.58 & $(-1.19$ to 0.04$)$ \\
\hline & Zhang et $a l^{13}$ & 193 & 230 & $248.95 \pm 75.71$ & $301.71 \pm 71.05$ & 15.60 & -0.72 & $(-0.92$ to -0.52$)$ \\
\hline & Sun et $a l^{15}$ & 204 & 194 & $234.00 \pm 67.73$ & $270.30 \pm 95.80$ & 15.56 & -0.44 & $(-0.64$ to -0.24$)$ \\
\hline & Jesús et $a l^{14}$ & 71 & 70 & $237.3 \pm 89.2$ & $278.4 \pm 77.9$ & 11.39 & -0.49 & $(-0.83$ to -0.16$)$ \\
\hline \multirow[t]{4}{*}{ Men } & Andreadou et a ${ }^{\rho}$ & 22 & 25 & $366.4 \pm 67.2$ & $427.7 \pm 124.9$ & 6.16 & -0.60 & $(-1.19$ to -0.01$)$ \\
\hline & Zhang et $a l^{13}$ & 341 & 384 & $294.60 \pm 89.21$ & $376.00 \pm 82.55$ & 16.91 & -0.95 & $(-1.10$ to -0.80$)$ \\
\hline & Sun et $a l^{15}$ & 207 & 202 & $252.62 \pm 87.75$ & $295.14 \pm 84.18$ & 15.62 & -0.49 & $(-0.69$ to -0.30$)$ \\
\hline & Jesús et al ${ }^{14}$ & 90 & 108 & $311.1 \pm 82.1$ & $346.2 \pm 95.8$ & 12.94 & -0.39 & $(-0.67$ to -0.11$)$ \\
\hline
\end{tabular}

the physiological functions of uric acid should go beyond antioxidation in humans. For instance, based on human epidemiological evidences it has been proposed that uric acid may act as a neurotransmitter and high levels of uric acid will decrease the risk of PD. ${ }^{27}$ This opinion gains evolutionary support that the levels of uric acid increased in humans due to the mutations in the uricase gene, ${ }^{28} 29$ which can be considered as an adaptive neurochemical compensation to the progressive nervous system. ${ }^{30}$ The comprehensive mechanisms underlying the association between uric acid and PD will be better understood with the better elucidation of the physiological functions of uric acid in future.

As it remains unclear whether the association between uric acid levels and PD is causal, more efforts are needed to comprehensively elucidate the biological basis underlying the gender differences as indicated by the meta-analysis. For instance, the sexual differences in uric acid levels, that is, men usually have higher uric acid levels (about $1 \mathrm{mg} / \mathrm{dL}$ ) than women with the same age due to the promotion of excretion of uric acid by oestrogen, may be one factor. In addition, it has been reported that the risk of PD occurrence differs significantly between men and women and higher incidence rate of $\mathrm{PD}$ in men was about 1.5 times greater than in women. ${ }^{31}$ Other factors, such as gender differences in levels of oestrogen, which was found to be neuroprotective, should also be taken into consideration. ${ }^{32}$

In four of the six studies the patients were divided into several subgroups according to H-Y stage diagnosis criteria. ${ }^{9} 13-15$ We cannot perform a meta-analysis on the correlation of serum uric acid levels with duration and progression of PD because the number of divided groups was different among these studies and also not enough data can be obtained to perform further analysis. However, these studies consistently showed an inverse correlation of uric acid levels with H-Y scales, and as the disease progressed, the serum uric acid levels gradually reduced. ${ }^{913-15}$

The major limitation of our study is the relatively limited available studies included in the meta-analysis. Another limitation is only the studies in English language were considered. In addition, the quality of the individual studies included in our study has not been assessed. Finally, patients with PD and their treatment with agents and lifestyle factors such as dietary habits
Figure 3 Pooled estimate of standardised mean difference (SMD) and $95 \% \mathrm{Cl}$ of uric acid levels in Parkinson's disease and healthy controls in women and men.

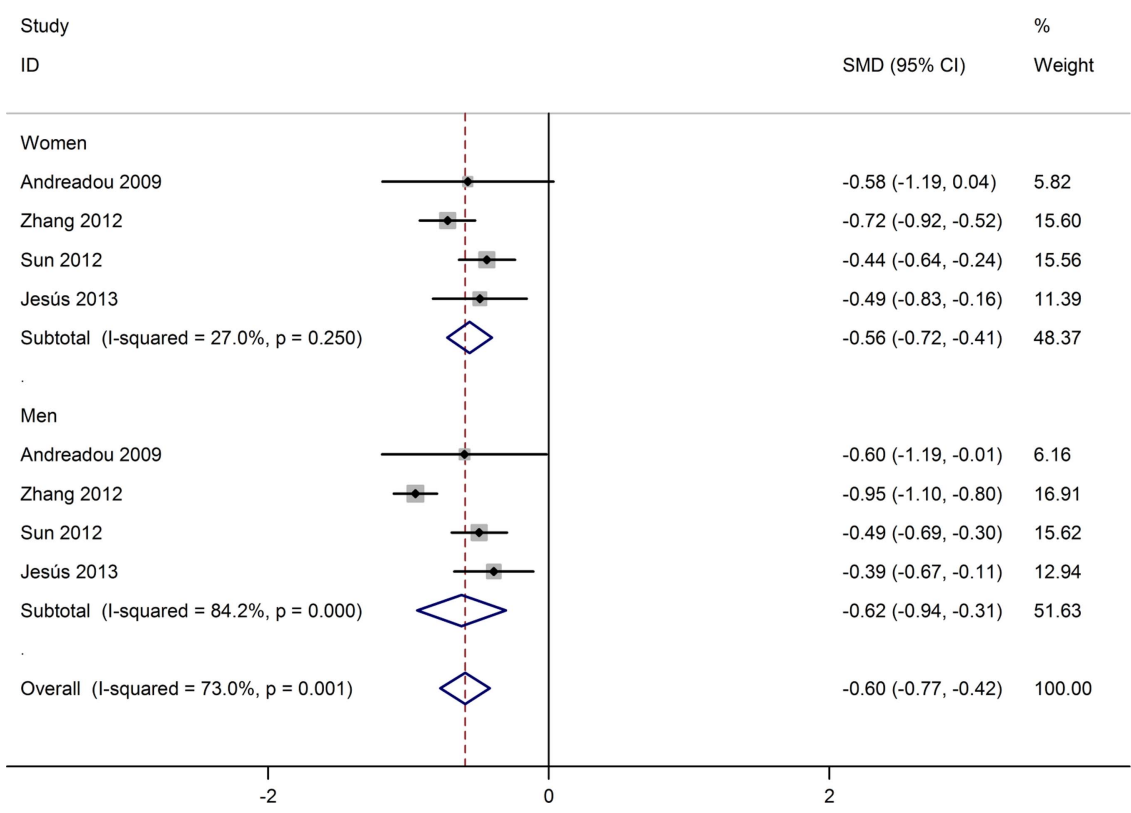


and physical exercise, might influence the metabolism of uric acid, ${ }^{33}$ while these factors cannot be considered in this meta-analysis.

\section{CONCLUSIONS}

In conclusion, this meta-analysis suggested that patients with PD had lower levels of uric acid than healthy controls and this association was more significant in men than in women. The evidence from the meta-analysis has implication that uric acid levels may potentially act as a biomarker for PD and its progression, which needs further verification especially after considering the gender differences. In addition, whether optimising uric acid levels, such as supplying adequate purine rich foods in diet of patients with PD to contribute to uric acid levels, is favourable for PD therapy also deserves further investigations.

Contributors HFJ designed the study. LS performed the meta-analysis. Both the authors performed the references selection and data abstraction, analysed the data, drafted and revised the manuscript and read and approved the final version of the manuscript.

Funding This research received no specific grant from any funding agency in the public, commercial or not-for-profit sectors.

Competing interests None.

Provenance and peer review Not commissioned; externally peer reviewed.

Data sharing statement All original data extraction are available from the corresponding author at jhf@sdut.edu.cn.

Open Access This is an Open Access article distributed in accordance with the Creative Commons Attribution Non Commercial (CC BY-NC 3.0) license, which permits others to distribute, remix, adapt, build upon this work noncommercially, and license their derivative works on different terms, provided the original work is properly cited and the use is non-commercial. See: http:// creativecommons.org/licenses/by-nc/3.0/

\section{REFERENCES}

1. Lang AE, Lozan AM. Parkinson's disease. N Engl J Med 1998;339:1044-53.

2. Davie CA. A review of Parkinson's disease. Br Med Bull 2008;86:109-27.

3. Beal MF. Mitochondria, oxidative damage, and inflammation in Parkinson's disease. Ann N Y Acad Sci 2003;991:120-31.

4. Ames BN, Cathcart R, Schwiers E, et al. Uric acid provides an antioxidant defense in humans against oxidant- and radical-caused aging and cancer a hypothesis. Proc Natl Acad Sci USA 1981;78:6858-62.

5. Church WH, Ward VL. Uric acid is reduced in the substantia nigra in Parkinson's disease: effect on dopamine oxidation. Brain Res Bull 1994;33:419-25.

6. Cipriani S, Chen X, Schwarzschild MA. Urate: a novel biomarker of Parkinson's disease risk, diagnosis and prognosis. Biomark Med 2010;4:701-12.

7. Alonso A, Sovell KA. Gout, hyperuricemia, and Parkinson's disease: a protective effect? Curr Rheumatol Rep 2010;12:149-55.

8. Annanmaki T, Muuronen A, Murros K. Low plasma uric acid level in Parkinson's disease. Mov Disord 2007;22:1133-7.

9. Andreadou E, Nikolaou C, Gournaras F, et al. Serum uric acid levels in patients with Parkinson's disease: their relationship to treatment and disease duration. Clin Neurol Neurosurg 2009;111:724-8.
10. O'Reilly EJ, Gao X, Weisskopf MG, et al. Plasma urate and Parkinson's disease in women. Am J Epidemiol 2010; 172:666-70.

11. Jain S, Ton TG, Boudreau RM, et al. The risk of Parkinson disease associated with urate in a community-based cohort of older adults. Neuroepidemiology 2011;36:223-9.

12. Annanmaki T, Pohja M, Parviainen T, et al. Uric acid and cognition in Parkinson's disease: a follow-up study. Parkinsonism Relat Disord 2011;17:333-7.

13. Zhang HN, Guo JF, He D, et al. Lower serum UA levels in Parkinson's disease patients in the Chinese population. Neurosci Lett 2012;514:152-5.

14. Jesús S, Pérez I, Cáceres-Redondo MT, et al. Low serum uric acid concentration in Parkinson's disease in southern Spain. Eur J Neurol 2013;20:208-10.

15. Sun CC, Luo FF, Wei L, et al. Association of serum uric acid levels with the progression of Parkinson's disease in Chinese patients. Chin Med J (Engl) 2012;125:583-7.

16. Jenner $P$, Olanow CW. Oxidative stress and the pathogenesis of Parkinson's disease. Neurology 1996;47(Suppl 3):S161-70.

17. Jomova K, Vondrakova D, Lawson M, et al. Metals, oxidative stress and neurodegenerative disorders. Mol Cell Biochem 2010;345:91-104.

18. Bowman GL, Shannon J, Frei B, et al. Uric acid as a CNS antioxidant. J Alzheimers Dis 2010;19:1331-6.

19. Davies KJ, Sevanian A, Muakkassah-Kelly SF, et al. Uric acid-iron ion complexes. A new aspect of the antioxidant functions of uric acid. Biochem J 1986;235:747-54.

20. Maxwell SR, Thomason H, Sandler D, et al. Antioxidant status in patients with uncomplicated insulin-dependent and non-insulin-dependent diabetes mellitus. Eur J Clin Invest 1997;27:484-90.

21. Hooper DC, Spitsin S, Kean RB, et al. Uric acid, a natural scavenger of peroxynitrite, in experimental allergic encephalomyelitis and multiple sclerosis. Proc Natl Acad Sci USA 1998;95:675-80.

22. Squadrito $\mathrm{GL}$, Cueto $\mathrm{R}$, Splenser $\mathrm{AE}$, et al. Reaction of uric acid with peroxynitrite and implications for the mechanism of neuroprotection by uric acid. Arch Biochem Biophys 2000;376:333-7.

23. Ebadi M, Sharma SK. Peroxynitrite and mitochondrial dysfunction in the pathogenesis of Parkinson's disease. Antioxid Redox Signal 2003;5:319-35.

24. Vauzour D, Ravaioli G, Vafeiadou K, et al. Peroxynitrite induced formation of the neurotoxins 5-S-cysteinyl-dopamine and DHBT-1: implications for Parkinson's disease and protection by polyphenols. Arch Biochem Biophys 2008;476:145-51.

25. Caulfield MJ, Munroe PB, O'Neill D, et al. SLC2A9 is a high-capacity urate transporter in humans. PLoS Med 2008;5:e197.

26. Facheris MF, Hicks AA, Minelli $\mathrm{C}$, et al. Variation in the uric acid transporter gene SLC2A9 and its association with AAO of Parkinson's disease. J Mol Neurosci 2011;43:246-50.

27. Bucay $\mathrm{AH}$. A new hypothesis about the role of uric acid as a neurotransmitter. Med Hypotheses 2009;73:854-65.

28. Oda M, Satta Y, Takenaka O, et al. Loss of urate oxidase activity in hominoids and its evolutionary implications. Mol Biol Evol 2002;19:640-53.

29. Wu XW, Muzny DM, Lee CC, et al. Two independent mutational events in the loss of urate oxidase during hominoid evolution. $J \mathrm{Mol}$ Evol 1992;34:78-84.

30. Shen L. Evolutionary support for the hypothesis about uric acid as a neurotransmitter. Med Hypotheses 2010;75:131-2.

31. Wooten GF, Currie LJ, Bovbjerg VE, et al. Are men at greater risk fo Parkinson's disease than women? J Neurol Neurosurg Psychiatry 2004;75:637-9.

32. Inestrosa NC, Marzolo MP, Bonnefont AB. Cellular and molecular basis for estrogen's neuroprotection. Potential relevance for Alzheimer's disease. Mol Neurobiol 1998;17:73-86.

33. Miao Z, Li C, Chen Y, et al. Dietary and lifestyle changes associated with high prevalence of hyperuricemia and gout in the Shandong coastal cities of Eastern China. J Rheumatol 2008; 35:1859-64.

34. Bierer DW, Quebbemann AJ. Effect of L-dopa on renal handling of uric acid. J Pharmacol Exp Ther 1982;223:55-9. 